\title{
Cultural Capital of a community to adapt in prone areas with floods, land subsidence and its Architectural representation. Case Study in Bandarharjo Semarang
}

\author{
Muchi Juma Ameir ${ }^{*}$, Agus S, Ekomadyo ${ }^{2}$, Cahyo Septianto Hutomo ${ }^{3}$ \\ 1,2Department of Architecture, Institute Teknologi Bandung,SAAPK, Indonesia \\ Corresponding Author: : muchildomuchildo@gmail.com
}

\begin{abstract}
Keywords: Indigenous Knowledge, culture Capital, Forms of Culture, adaptation to disaster (floods and land subsidence), Architectural representation.

Along with the rapid development of technology, local wisdom tends to run into marginalization so that it is completely lost (Choesin, 2002 cited in Rasna\&Tantra, 2017). The local wisdom should be able to become a milestone in the community in order to preserve the cultural heritage and the natural resources. Meanwhile, a transformation towards sustainability is urgently needed for our planet, and every other living thing on it including the resources it provides. Therefore, this study aims at exploring the local wisdoms that still exist and develops at several springs in Singosari Malang. Locations were chosen based on the profile of the springs which still have good management based on the local wisdom that are passed on through generations. The springs include Sumber Biru and Sumber Nagan in Gunungrejo village, Singosari District Malang. The research approach used is ethnographic research. Interviews, focused discussions, and documentation were the techniques used to collect the data. The result is descriptively presented in a form of a history of the springs which is retold in the form of short story.
\end{abstract}

DOI: https://doi.org/10.26905/lw.v12i1.3704

@ 2017 The Authors. Published by GKAK UNMER Malang

*Corresponding Author: muchildomuchildo@gmail.com

\section{Introduction}

Indonesia is one among the Far East Asian countries that faces a lot of disaster and thus community have their own methods of coping to the disaster conditions relating to the type of disaster such as floods hazards (Shaw, Uy, \& Baumwoll, 2008).Thus they used their own way to mitigate the hazard by using the local understanding and indigenous knowledge, this indigenous knowledge have been transferred to the different generation so as to spread the concept of indigenous understanding that has been distributed through the community leaders and descendants to mitigate the disaster situation and survived from difficult circumstances (Dewi, 2007), Community can use their abilities to cope with the severe disruption and overcome the situation from the loss of materials or environment(Smith \& Ward, 1998). 


\section{Cultural Capital of a community to adapt in prone areas with floods, land subsidence and its Architectural representation. Case Study in Bandarharjo Semarang Muchi Juma Ameir, Agus S, Ekomadyo' Cahyo Septianto Hutomo}

So many reasons together created the situation of community such as from Bandarharjo to stay by adapting the environmental disaster, reasons include city structure where as it is close to the Kota Semarang, cultural potential, livelihood and economic purposes. Human realization has altered the environment as action and reaction to the life system,community usualliving in this area for decades due to the structure of the economy and the city structure.In most cases Government try to find the alternatives in finding shelter for them in other areas but it is still in process but yet they still choose to live in the same areas, having their own integrity and social structure they perform daily activities by adapting with the nature by coping with floods and land subsidence. The alterations would be the physical change i.e. arrangement, material, space and the nonphysical change i.e. meanings (Rapoport, 2006).

The built environment in this paper will be much concerned on prone areas to disaster that faces north part of Semarang in Central Java,KampungBandar Harjo is the selected area for the analysis of the example and it will be used as a case study for this paper, this area is located among the high prone areas with dense population and poor social level together with Kelurahan Panggung Kidul, Dadapsari, Kuningan, Kemijen and Tanjung Emas. The disaster includes tidal floods, flash floods and land subsidence has been experienced a lot Anang Wahyu Sejati, (2010).The community of northern part of Semarang is living in vulnerable situation of clean water availability in the future as they quiet rely on the water supply company for their daily needs, without thinking other alternatives methods to reduce strong dependence when they face disaster (Wijaya, 2015).

This paper as a learning process is to understand and identify how the community be able to adapt with the environment through time in a built environment by inheritance of indigenous knowledge transferred from generation to generation and use that knowledge as part of the mitigation culture, adaptation by the use of local skills and materials with its applicability in the related environment. Specific objective is to understand the architectural representation of mitigation manners in Kampung Bandarharjo by using the theory of Cultural Capital from Forms of Capital by (Bourdieu, 1986).

\section{Literature Review}

Culture consists of patterns, explicit and implicit, of and for behaviour acquired and transmitted by symbols, constituting the distinctive achievements of human groups, including their embodiment in artifacts; the essential core of culture consists of traditional (i.e. historically derived and selected) ideas and especially their attached values; culture systems may, on the one hand, be considered as products of action, on the other, as conditional elements of future action(Spencer-Oatey, 2012).

The idea of using use of indigenous knowledge when define and provide better understanding in Local culture and translate it into architectural perspective can be changed following the global competitiveness and changed it to global economic due to the condition of production and consumption, the role of architecture in this transformation could be categorized in three, namely the creativity of architectural transformation in the reproduction of local culture, the creation of places (place-making) for the consumption of local culture, and the delivery of noble messages of local culture through architecture. (Ekomadyo, 2014) 


\section{LOCAL WISDOM, Vol. 12 No. January 2020}

Local Wisdom Scientific Online Journal

Theory to be used for this paper includes the Theory from Cultural Capital from Forms of Capital by (Bourdieu, 1986), this theory can be used to identify the indigenous knowledge used and its criteria for specific area with the community of same interest.

Different location with different communities experience different hazards, but they all adapt with the environment by adopting knowledge and implement through their own living culture. Depends on the location the use of skills and knowledge that can be utilized to gain the possible solution, other society depends on financial capabilities to the fulfill and run their dreams. The distribution of the capital defines and interprets the society at a given time and elaborates on their status of living, it is as well categorized in immaterial culture, social culture and economy based. The economy form of culture it has both sides where as it can produce a profit but at the same time it can show its negative side, every output depends on the profit and economic interest with price tag of every products and converted into money (Bourdieu, 1986).

\section{Forms of Capital categorized in}

Economic Capital: economy based on the money and the property right of use, basically it is institutionalized.

Social Capital: trust, social Relationship: based on nobility:

Cultural Capital: based on educational qualifications.

Symbolic Capital: monuments, iconic buildings.

\section{Theory of Cultural capital}

Cultural capital is categorized by three major elements which are depending different experiences depends on the location and activities based on the specific area or regions, those experience are coming with different talents such as manners, credentials, skills, dances, music, sports, education. These cultural capitals represent the community and strengthen the way of living and their cultural perspective without using financial capital. The Cultural Capital is measured by how much value society places on non-financial assets.

1. Institutionalized: education or specialized knowledge.

2. Objectified: books, instruments, machines or other belonging's

3. Embodied: personality, speech, skills.

Having the perception of being knowledgeable to perform the given work or project by using identified educational process as a means of applying the thoughts and ideas on solving the matter in the society by referring to the scholars and academic facts. Those who falls under these categories distinct from other with their grades and levels of educations relating to their professionalism (knowledge).

The objectified state cultural capital reflects to the useful objects from the society that can be used for generating something depends on the circumstances, in case of construction the societies has come to create their own tools to accomplish their schemes, the tools related to machines that been used for sometimes in a history so as to make it proficiently. It can be generalized the historical tools and the new machine or equipment's relating to the work they want to achieve, these tools also can represent those who craft them or those who knew well to utilize them for the best invention and also reflecting the verse culture (tools/ users).

The embodied refers to one personal ego and feeling towards success, the maturity from ones habits to the mind full of self-confidence and develop something from his personality and thus presenting the skills wisely through the words that can last longer and being memorable and useful (skills) 
Cultural Capital of a community to adapt in prone areas with floods, land subsidence and its Architectural representation. Case Study in Bandarharjo Semarang

Muchi Juma Ameir, Agus S, Ekomadyo Cahyo Septianto Hutomo

A Bourdieusian concept of cultural capital is used to investigate the transformations and contestations of migrants' cultural capital. He explains about the movement of the migrants to cross the borders with their different ethnically and cultural resources where as they tend to migrate and carry on their own characters that can influence and build their own cultural aspects and reproduces intra migrant differentiations of gender, ethnicity and class, in the process of adapting new alternatives to national capital.

\section{Research Methodology}

Methods to be used in this paper will be Qualitative methods and will focus on understanding the cultural mitigation approaches by considering the theory of Culture Capital from (Bourdieu, 1986). The reason for this paper is to understand the theory and relation with adaptability of the community in the context by using the indigenous knowledge and how to translate them into architectural representation on mitigation manners in area Kampung Bandarharjo, Semarang.

\subsection{Data collection Method}

The methods used to identify the indigenous knowledge in mitigation culture of the community of Bandarharjo area is including the understanding of the location and general information's of the study area by data collection. The methods will includes observation from the site/field survey, interviews and documentation.

Site Location of the Study.

Bandarhajo is one among the northern part of Semarang that experience the flood hazard, the surrounding area has got two floods from rivers and rain water. This problem goes together with the land subsidence which is high due to the over exploitation of ground water(Dewi, 2007), after Suanta(2002).See Figure 1.

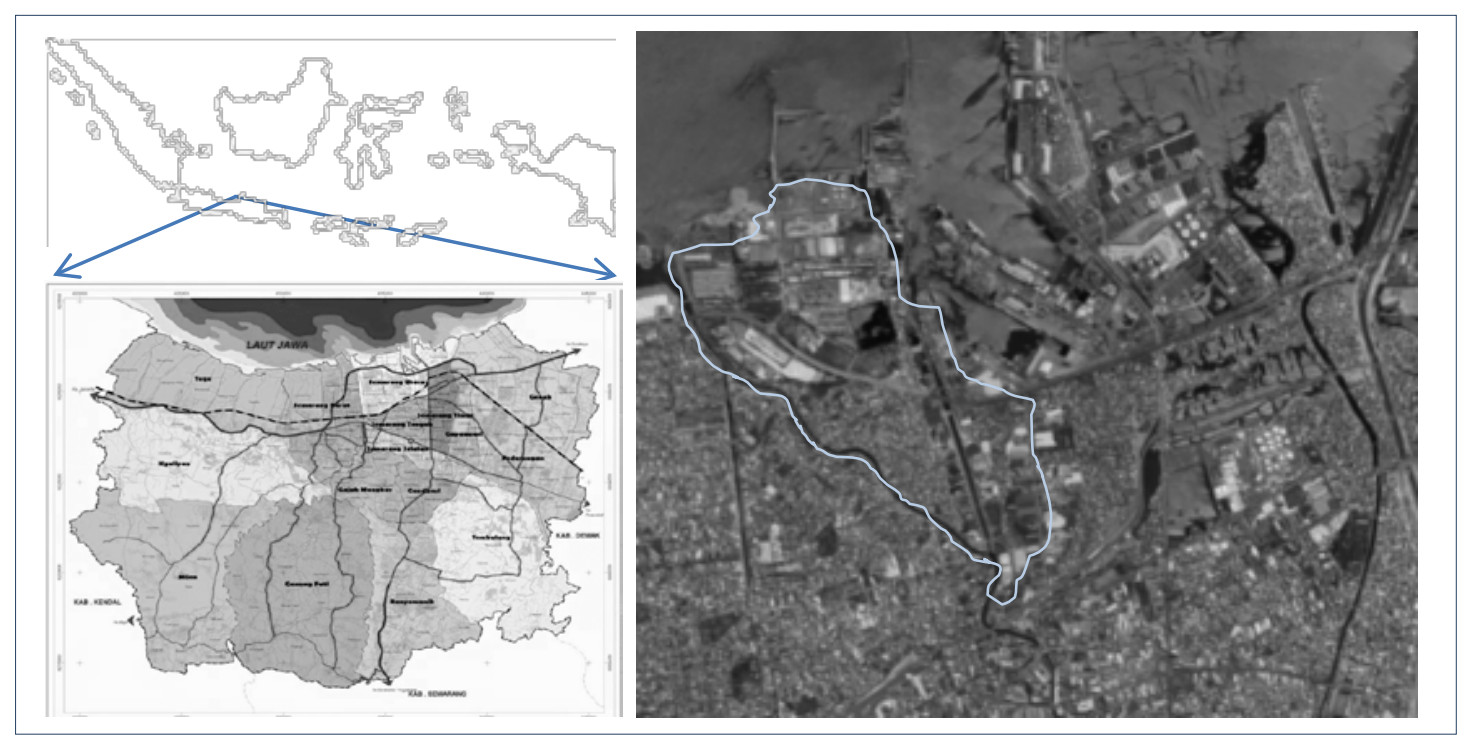

Figure 1. Shows the location Map Bandarharjo

(Source from Google Maps, 2019) 


\section{Result and Discussion}

(Dekens, 2007) has provided a synopsis of the different types of local knowledge (herein interchangeably used with indigenous knowledge) in order to explain the diversity of Indigenous Knowledge. The types of local knowledge, according to (Dekens, 2007), include local technical knowledge, environmental and agricultural knowledge, and social cultural and historical knowledge.

Indigenous knowledge has been introduced as the methods to adapt with the local environment in hazard areas, knowledge from the community can be well interpreted architectural in the technological advancements and be used for the future. This knowledge can be characterized differently with other forms of knowledge such as mostly it is originating from the similar people with the same interest and locality with nonformal communication strategies; it belongs to all the community in all generations that accepted adaptation with the survival instinct.

(Cadrin et al., n.d.).

For the community that already face the disaster in the past they usual find the way to overcome or to coping with the expected situation in the future by reflecting the past and assumptions from the similar event, thus from the assumptions made the knowledge is regenerated and being used to cope with the environment by using experience from the people who already face that situation before, (Blaikie, et.al. 2005). Some of the mitigation manners that have been used from Bandarharjo community to adapt with flood and land subsidence can be categorized into three aspects: environmental, building methods and material used. This will base upon economic, technological/ structural and social and giving the reflection to architectural representation.

\section{Environmental Strategies.}

As they are surrounded by water and dry land thus among the environmental strategy they used is also netting on the rubbish where they also used them in the filling process of the houses, with the scattered rubbish that floating near by the water they used nets so as to keep the environment clean but also the make them as a flood protection by keeping the land safe.

\section{Construction Methods.}

The earlier houses were built in tilt and then they started using red burnt bricks for their construction which were not expensive and available in local shops nearby the community living area, they are aware of the possibilities of floods and unseen land subsidence that happened very gradually thus the all new constructions are raised in more height of the ground floors as the mitigation methods. Due to the economic structure from outside of the area there is also a tendency of using raised concrete type of construction from single story to double stories depends on the economic status, rather it doesn't solve the long run of the subsidence.

Some of the construction methods founded in the site that following Indigenous practices are as follows with the architectural representation in Kampung Bandar Harjo.

\section{- Raised existing part of dwelling areas -mitigating flood impact.}

Elevating the house at ground level and other remaining from the house and nearby so as to increase the plinth height of the house, the level inside the house could be differentiated with the older one to be at lower level and the new one to be extra height up to $45 \mathrm{~cm}$. This can help when there is flooding and the other raised floor could be used 
Cultural Capital of a community to adapt in prone areas with floods, land subsidence and its Architectural representation. Case Study in Bandarharjo Semarang

Muchi Juma Ameir, Agus S, Ekomadyo Cahyo Septianto Hutomo

for both day to day activities such as kitchen area for cooking, living area and storage such as water and food. The process locally can be termed as "di uruk" and can be used when the building already sunk in such away it can no longer match with the flood problem, see Figure 2below.
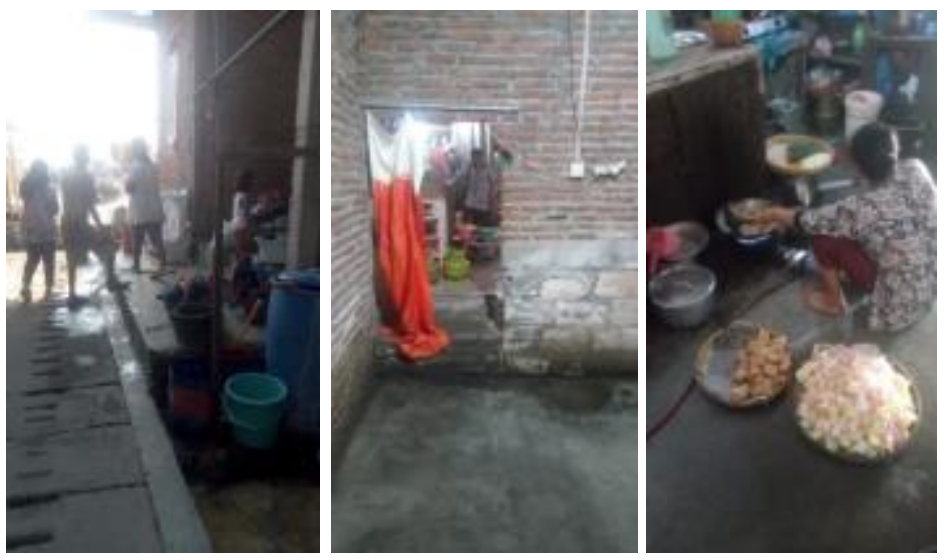

Figure2. Shows the leveling of the house from the inside and outside for various use.

(Source: taken from the site 22 Oct 2019)

\section{- New reconstructed houses on raised plinths - avoiding inundation.}

The new constructions of the housing structures have been raised as to leave the house by avoiding inundation, the ground floor of the house can be accessed by stairs of about 0.6 to 1 meter. These types of the houses are constructed on top of the deteriorated ones and also them collecting the waste nearby and fill it to the foundation before constructing the ring beam at the foundation. See Figure 3below.
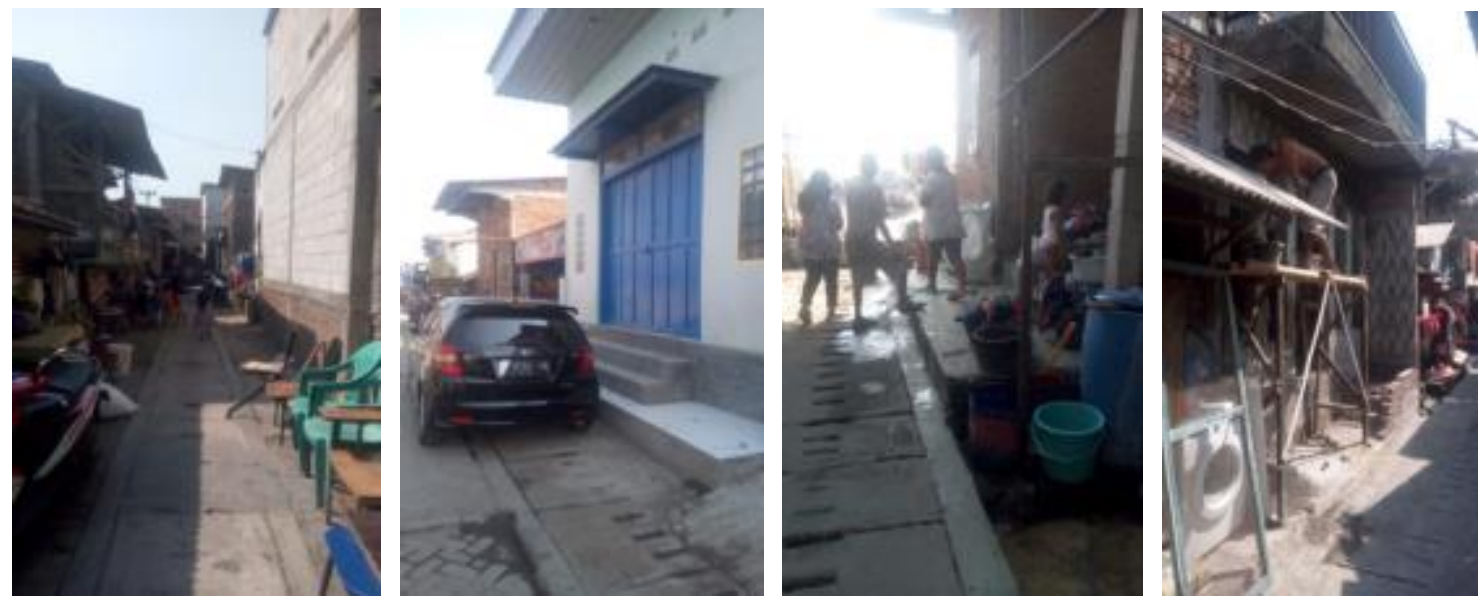

Figure3. Shows raised plinth houses.

(Source: taken from the site 22 Oct 2019) 
- Growing vegetables on plinths or damping of un- used wooden materials mitigating flood impact.

The vegetables on the plinth can be also used for mitigation of floods by absorbing few amounts of the water and reduce the moistures inside the house, in normal days they can be used as the vegetables and gardens. Some areas they keep the unused bamboo as flood mitigation, see Figure 4below.

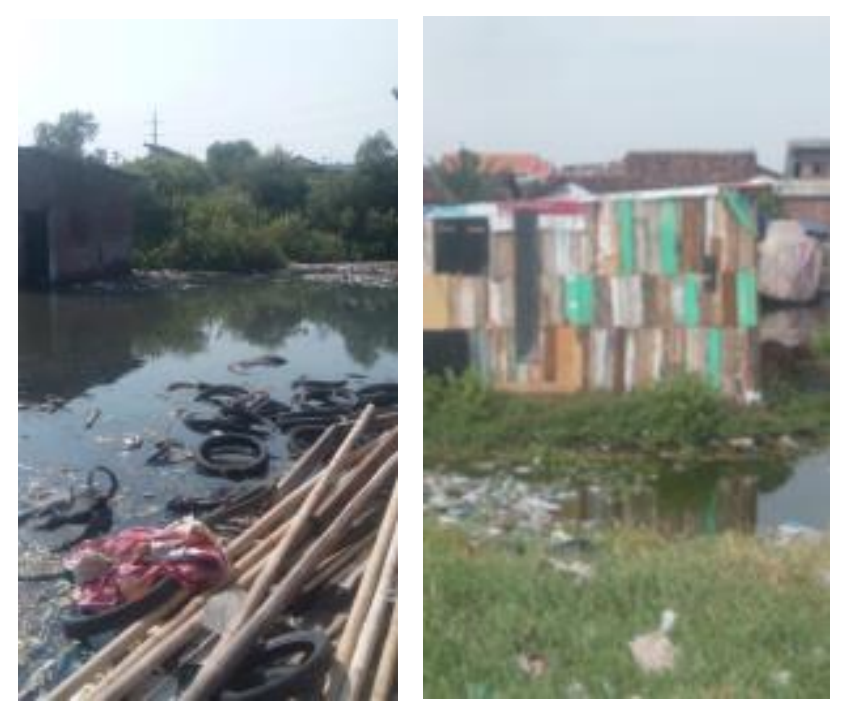

Figure 4. Shows the un used wooden structure and green areas nearby the houses.

(Source: taken from the site 22 Oct 2019)

\section{- Leveling the in front door spaces partially.}

Using local available materials that can be placed at entrance door for blocking of flash flood to enter the house during floods, this small piece of either wooden or metal sheet can be used as a stopper of the water to enter the building and reduce damage inside. This idea used for all houses that are already semi sink before deciding to fill inside " $d i$ uruk" house floor, see Figure 4 below.
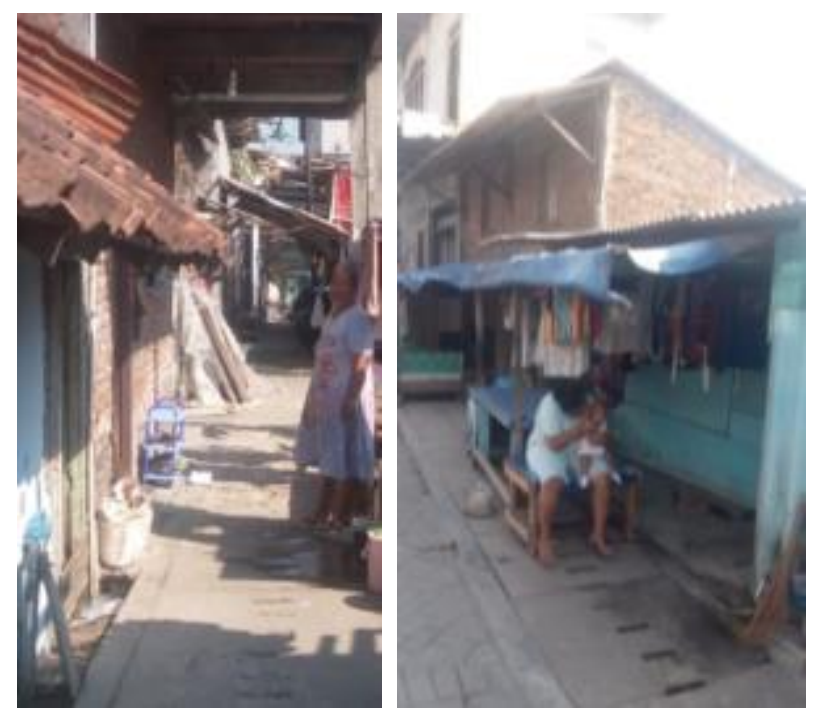

Figure4. Shows the door stopper at the entrance to protect the water not to enter the house (Source: taken from the site 22 Oct 2019) 
Cultural Capital of a community to adapt in prone areas with floods, land subsidence and its Architectural representation. Case Study in Bandarharjo Semarang

Muchi Juma Ameir, Agus S, Ekomadyo. Cahyo Septianto Hutomo

- Filling the houses with some materials to raise the floor level and sides.

Different materials are used includes soil, cement and tile/ceramic as water proofing from ground "seeping" and sides walls .See Figure 5.
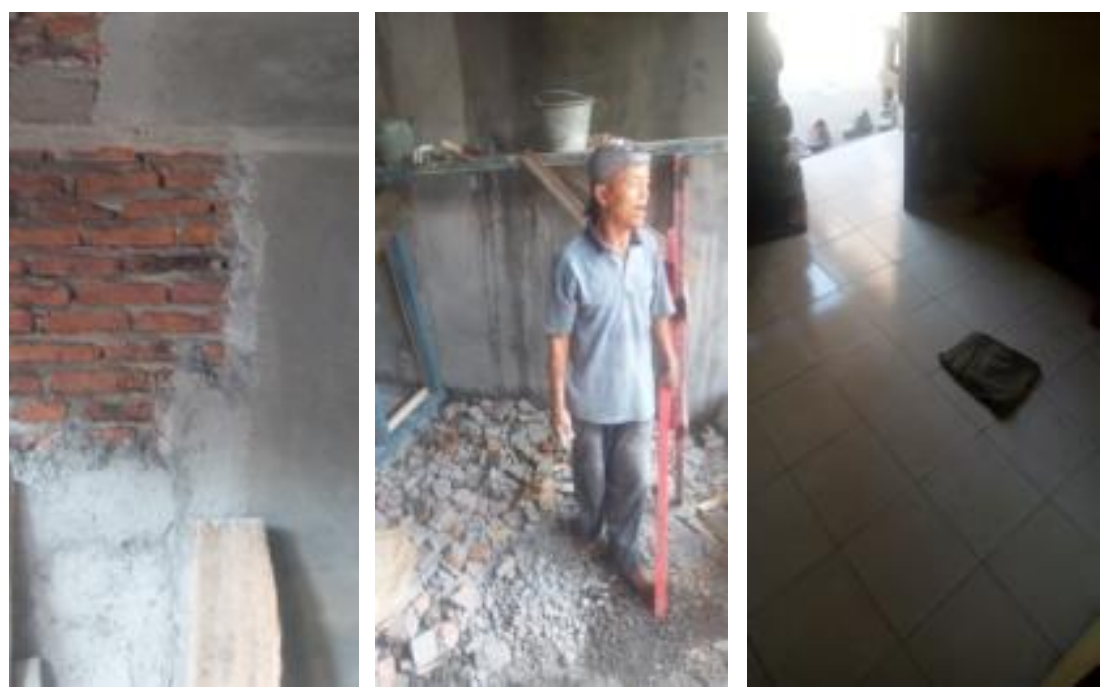

Figure 5. Different materials used for raising and waterproofing on the floor and the walls. (Source: taken from the site 22 Oct 2019)

- Using tilt structures for keeping poultry farm and food storage.

Mitigation of flood, utensils and food preservation. This can ensure all seasons in the time of flood or after floods; structures can be outside or inside the houses. It usual constructed by remains of the boards and aluminum sheets as to protect from rain water. All materials used are easy to fix and affordable with significant purposes.
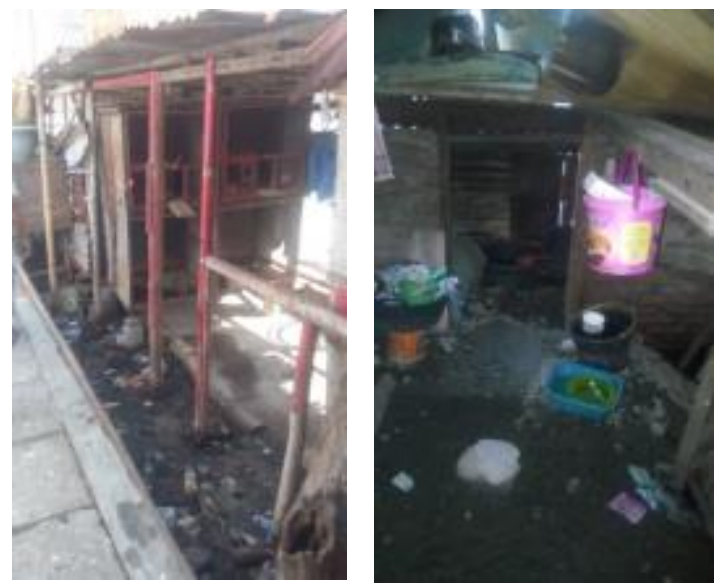

Figure6.Shows the overhead structures with different materials used for storage purposes. (Source: taken from the site 22 Oct 2019)

From discussion refers to the findings at the site and interviews with the community from Bandarharjo, the researcher found some of the criteria based on the theory of Culture Capital from Boudier, $\mathrm{P}(1986)$ have been used to identify the indigenous knowledge used to mitigate against the flood hazard and land subsidence. That's including using of skills, knowledge, manners and credentials that the community have been inherit and familiarized through their context, these practices with the community 
can also contribute the meaning of traditional practices, experienced based, community trusted and reliance with the local available resources.

\section{Conclusion}

From the findings during the field visit together and literature reviewresearcher found that Indigenous practice characterized from traditional practice, experience base, community trusted and reliant on locally available resources or by products of the household materials that can be well utilized for the inhabitants to survive in the disaster context, this can be also the low cost strategies to be used in the community as the preliminary mitigation to minimize the disaster. The theory of mitigation can be direct linked with Cultural Capital from Boudier(1986)that's explain the way group of people who are familiarized with the context can use their knowledge to adapt with the environment by applying traditional practices by their experiences and use the available materials to mitigate with the hazard.

This respective indigenous knowledge can be adapted and translated by the respective Institutions with policy supports and stakeholders to adapt them into the technological advancement for the purpose of future use, this indigenous knowledge have to be documented. There is a need to give awareness to the community, who are living in natural disaster context on how to link the indigenous knowledge with disaster education as to improve disaster risk reduction in the respective areas. As suggested by (Dewi, 2007), workshops can be used to get necessary understandings between the stakeholders.

A community based approach can be used as affective way to spread the knowledge and understanding of people's perception on coping with the disaster by initiating livelihood systems and monitoring the effects at community level and builds the resilience community, thus to sayindigenous knowledge has rationality with indigenous architecture as it reflects on identity, location, land, territory, culture and language. Indigenous knowledge has the future significance to sustain the indigenous architecture (Stewart, 2015).

\section{References}

Blaikie, P., Cannon, T., Davis, I., \& Wisner, B. (2005). At risk: natural hazards, people's vulnerability and disasters. Routledge.

Bourdieu, P. (1986). The Forms of Capital." Handbook of Theory and Research in the Sociology of Education, ed. J. Richardson. Westport, CT: Greenwood Press.

Cadrin, M., Rana, M. S., Sarker, K. H., Rahman, K. S., Kamal, M. M., Hussain, Z., ... Hasan, M. M. (n.d.). Local Wisdom: Indigenous Practices for Mitigating Disaster Loss.

Dekens, J. (2007). The snake and the river don't run straight: local knowledge on disaster preparedness in the Eastern Terai of Nepal. International Centre for Integrated Mountain Development (ICIMOD).

Dewi, A. (2007). Community-based analysis of coping with urban flooding: a case study in Semarang, Indonesia. ITC.

Marfai, M. A. (2003). GIS Modelling of river and tidal flood hazards in a waterfront city. Case Study: Semarang City, Central Java, Indonesia. 
Cultural Capital of a community to adapt in prone areas with floods, land subsidence and its Architectural representation. Case Study in Bandarharjo Semarang

Muchi Juma Ameir, Agus S, Ekomadyo. Cahyo Septianto Hutomo

Rapoport, A. (2006). Local environments in a global context. Ekistics, 122-131.

Shaw, R., Uy, N., \& Baumwoll, J. (2008). Indigenous knowledge for disaster risk reduction: Good practices and lessons learned from experiences in the Asia-Pacific Region. United Nations, International Strategy for Disaster Reduction.

Smith, K., \& Ward, R. (1998). Floods: physical processes and human impacts. John Wiley and Sons Ltd.

Spencer-Oatey, H. (2012). What is culture? A compilation of quotations. GlobalPAD Core Concepts.

Stewart, P. (2015). Indigenous architecture through indigenous knowledge. PhD Diss., University of British Columbia.

Wijaya, N. (2015). Climate change adaption measures in the coastal city of Semarang, Indonesia: current practices and performance. Journal of Regional and City Planning, $26(1), 28-42$. 